\title{
Mammary Gland Type Features Present
}

National Cancer Institute

\section{Source}

National Cancer Institute. Mammary Gland Type Features Present. NCI Thesaurus. Code C128163.

A microscopic finding indicating the presence of mammary gland type morphological features in a tumor sample. 